\title{
Determination of activated lymphocytes in peripheral blood of patients with multiple sclerosis
}

\author{
A D CROCKARD, T A McNEILL, J McKIRGAN, S A HAWKINS
}

From the Departments of Microbiology and Immunobiology, and Medicine, Queen's University of Belfast, Royal Victoria Hospital, Belfast, Northern Ireland

SUMMARY Using monoclonal antibodies Tal and CD25 (interleukin-2 receptor: I-2R) and flow cytometry, the levels of activated lymphocytes in the peripheral blood of 50 patients with multiple sclerosis (16 relapsing inactive; 14 relapsing active; 20 chronic progressive) and 20 normal subjects were investigated. No significant differences were observed in the percentage or absolute numbers of Tal and IL-2R reactive lymphocytes between the normal and multiple sclerosis patient groups, irrespective of disease activity. Monitoring peripheral blood lymphocytes with respect to these markers would appear to have little value in the management of multiple sclerosis.

During the last decade the immune status of patients with multiple sclerosis has been extensively studied and in particular the distribution and function of various monoclonal antibody defined lymphocyte subpopulations. Despite numerous investigations no clear consensus of opinion exists as to the relationship between numbers of $T$ cells and their subsets with disease activity. ${ }^{1-6}$

More recently attention has focused on the role of activated $T$ cells in multiple sclerosis and, using monoclonal antibodies, several investigators have demonstrated the presence of these cells in peripheral blood and cerebrospinal fluid (CSF) of multiple sclerosis patients. ${ }^{7-13}$ The monoclonal antibody Tal has been reported as identifying a human $\mathrm{T}$ cell specific activation antigen. ${ }^{14}$ Using this reagent Hafler $e t a l^{9}$ have reported that a majority of patients with chronic progressive multiple sclerosis have elevated levels of $\mathrm{Tal}^{+}$cells in the peripheral blood compared with patients with stable multiple sclerosis, other neurological diseases or normal controls. In contrast, lymphocytes displaying other activation antigens (interleukin-2 receptor, IL-2R; T113) were not found to be increased. Thus it was suggested that the identification and monitoring of $\mathrm{Tal}^{+}$cells may provide a useful objective measurement of immu-

Address for reprint requests: Dr A D Crockard, Dept. Microbiology and Immunobiology, Queen's University of Belfast, Royal Victoria Hospital, Grosvenor Road, Belfast BT12 6BN, Northern Ireland.

Received 16 June 1987. Accepted 20 July 1987 nological activity in multiple sclerosis.

In this study we have investigated, using flow cytometry, the numbers of activated lymphocytes $\left(\mathrm{Tal}^{+}\right.$,

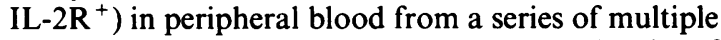
sclerosis patients and normal subjects, with the aim of determining the levels of these cells in multiple sclerosis patients and their relevance to disease activity. In addition, a lymphocyte phenotypic profile (T, T helper, $T$ suppressor, B, natural killer cells) was obtained in all cases.

\section{Patients, materials and methods}

Fifty patients with multiple sclerosis and 20 normal subjects were studied. All patients had clinically definite multiple sclerosis or progressive probable multiple sclerosis according to the criteria of McDonald \& Halliday. ${ }^{15}$ No patients had received steroids within the previous 3 months; none had been treated with an immunosuppressive drug other than steroids. Relapsing/remitting cases (30) were classified as active (14), if they had been in relapse within the previous 1 month, with new symptoms and signs which had not previously existed, or an exacerbation of previously existing signs. The term progressive multiple sclerosis represents patients (20) who had experienced a steady deterioration in symptoms and signs over the previous 6 months without any sudden deterioration.

Heparinised blood samples $(5 \mathrm{ml})$ were obtained from patients and control subjects and lymphocyte subpopulations identified using monoclonal antibodies and flow cytometry. Briefly, $100 \mu \mathrm{l}$ aliquots of blood were incubated for $15 \mathrm{~min}$, on ice, with $5 \mu \mathrm{l}$ of the respective monoclonal antibodies: OKT11 (CD2); OKT3 (CD3); OKT4 
(CD4); OKT8 (CD8); OKB7; (Ortho-Mune) or $10 \mu$ of Leu 7; IL-2R (CD25); (Becton Dickinson). Following two washes in phosphate buffered saline (PBS) (3 min, $400 \mathrm{~g}$ ), $100 \mu \mathrm{l}$ of (1:20) goat anti mouse IgG-FITC (Ortho) was added to the respective preparations and a further incubation $(15 \mathrm{~min})$ on ice performed. Using monoclonal antibody Tal (Coulter Clone), which is directly conjugated to phycoerythrin, a $30 \mathrm{~min}$ staining period was employed. Appropriate controls for background staining were included in each assay. Following incubation with conjugated antibodies, all blood samples were washed twice in PBS and red cells lysed using Whole Blood Quick Stain Lysing Reagent (Coulter Immunology). The remaining leukocytes were resuspended in a $1 \%$ paraformaldehyde-PBS solution. Analyses were performed on an EPICS 541 flow cytometer (Coulter Electronics Ltd). Lymphocyte populations were identified on the basis of forward and $90^{\circ}$ light scatter signals and gated appropriately. Single parameter log green or red signals were obtained from the gated populations. Five thousand lymphocytes were counted in each sample and the percentage of positive cells determined using the instrument's Immuno programme.

Statistical analyses were performed using the Mann Whitney $\mathrm{U}$ test.

\section{Results}

The percentages and absolute numbers of $\mathrm{Tal}^{+}$and IL-2 $\mathbf{R}^{+}$cells determined in the multiple sclerosis patient and normal control groups are shown in the table. No statistically significant differences were observed in either the percentages or absolute numbers of $\mathrm{Tal}^{+}$cells between the controls and multiple sclerosis patients, nor between the clinically defined patient groups. Using 2 standard deviations from the mean values obtained for $\mathrm{Ta}^{+}$cells from control subjects as the upper limit of normal $(58 \%$; $1.32 \times 10^{9} / 1$ ), three patients (one inactive, one active, one progressive) demonstrated increased percentages of $\mathrm{Tal}^{+}$cells $(60 \% ; 65 \% ; 61 \%$ respectively), although the absolute number of circulating $\mathrm{Tal}^{+}$ cells was not above the normal limit.

Representative fluorescence profiles obtained for Tal are shown in the fig, a, b. The most frequently observed profile was that shown in figure (a) (41/50 multiple sclerosis patients; 16.20 normals). The implications of these differences in $\mathrm{Tal}$ reactivity are unclear at present as we were unable to relate the
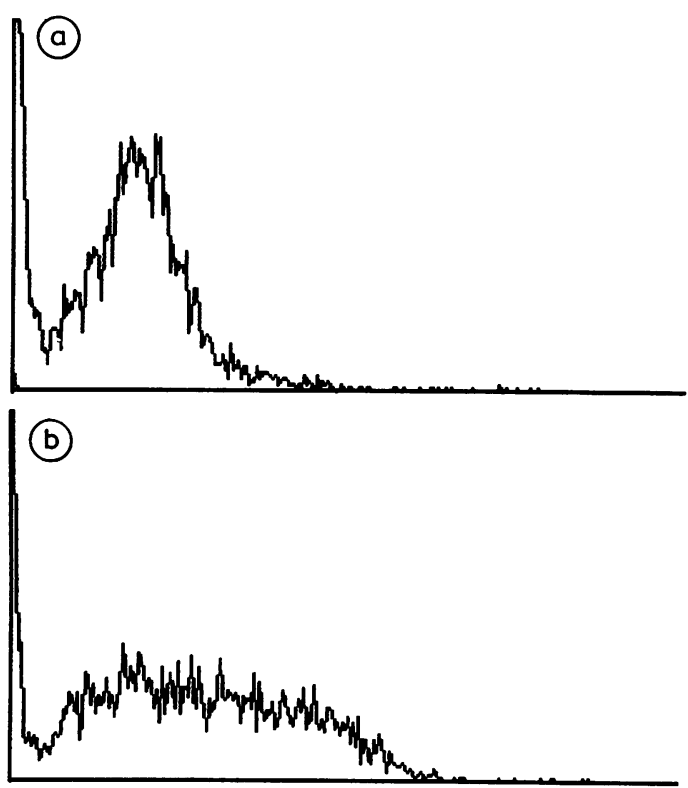

Fig Fluorescent histograms obtained for lymphocytes stained with phycoerythrin-conjugated Tal. ( $x$ axis: fluorescence intensity; $y$ axis: relative cell number). (a) and (b): distinctive profiles observed in two multiple sclerosis patients with relapsing disease.

profile type to other immunological or clinical features.

A low percentage of IL-2R ${ }^{+}$cells was observed in the normal $(4 \pm 1 \%)$ and patient groups (relapsing inactive: $3 \pm 1 \%$; relapsing active: $3 \pm 1 \%$; chronic progressive: $4 \pm 1 \%$ ). Again no statistically significant differences were observed between normals and patients irrespective of disease activity.

The percentages and total numbers of the respective $T, T$ subset, $B$ and NK cells did not differ between patient groups or between patient groups and normal controls (data not shown).

\section{Discussion}

In this study we did not observe differences in Tal reactivity in peripheral blood lymphocytes from

Table Tal and $I L-2 R$ reactive lymphocytes in peripheral blood from multiple sclerosis patients and normal subjects $($ Mean $\pm S E M)$

\begin{tabular}{|c|c|c|c|c|c|}
\hline & & \multicolumn{2}{|l|}{ Tal } & \multicolumn{2}{|l|}{$I L-2 R$} \\
\hline & & $\%$ & $\times 10^{9} / l$ & $\%$ & $\times 10^{9} / l$ \\
\hline $\begin{array}{l}\text { Relapsing inactive multiple sclerosis } \\
\text { Relapsing active multiple sclerosis } \\
\text { Chronic progressive multiple sclerosis } \\
\text { Normal subjects }\end{array}$ & $\begin{array}{l}(16) \\
(14) \\
(20) \\
(20)\end{array}$ & $\begin{array}{l}30 \pm 4 \\
33 \pm 4 \\
27 \pm 3 \\
32 \pm 3\end{array}$ & $\begin{array}{l}0.50 \pm 0.08 \\
0.62 \pm 0.11 \\
0.51 \pm 0.06 \\
0.62 \pm 0.08\end{array}$ & $\begin{array}{l}3 \pm 1 \\
3 \pm 1 \\
4 \pm 1 \\
4 \pm 1\end{array}$ & $\begin{array}{l}0.04 \pm 0.01 \\
0.05 \pm 0.01 \\
0.06 \pm 0.01 \\
0.08 \pm 0.02\end{array}$ \\
\hline
\end{tabular}


normal donors or multiple sclerosis patients. Similarly, in the patient groups there was no relationship between the numbers of $\mathrm{Tal}^{+}$cells and disease activity. These findings contrast with those of Hafler $e t a l^{9}$ who reported elevated numbers of $\mathrm{Ta}{ }^{+}$lymphocytes in peripheral blood of 20 of 35 patients with chronic progressive multiple sclerosis and four of 18 cases of stable or improving disease. In addition, the percentages of Tal reactive cells reported by these investigators were substantially lower (normals: $6 \pm 1 \%$; progressive multiple sclerosis $16 \pm 1 \%$; stable or improving multiple sclerosis $11 \pm 1 \%$ ) than obtained in this study (table). This discrepancy could be due to the methods used to collect fluorescent signals in the flow cytometer. In the study of Hafler $\boldsymbol{e t}$ $a l^{9}$ analyses were based on the (less sensitive) collection of linear as opposed to the more conventional log amplified signals used in the present study.

Recently it has been reported that the Tal monoclonal antibody identifies antigen reactive memory $T$ cells. ${ }^{16}$ The fact that this population may include $T$ cells which are reactive with autoantigens makes it interesting to speculate on the possible role of these cells in autoimmune disease. However, in view of our findings of relatively high numbers of $\mathrm{Ta}^{+}$cells and the similarity between normals and multiple sclerosis patients, further investigation of the functions of $\mathrm{Tal}^{+}$cells is warranted.

Low levels of IL-2R lymphocytes were observed in peripheral blood of both normal donors and multiple sclerosis patients. This is a consistent finding in multiple sclerosis where increases in IL- $2 \mathrm{R}^{+}$cells are negligible or modest. ${ }^{9-1113}$ However, significantly elevated numbers of $I L-2 R^{+}$cells can be demonstrated in the CSF. ${ }^{1011}$ Whether this reflects local activation within the CSF or recruitment from the periphery is unclear at present.

In conclusion, using two markers of lymphocyte activation (Tal, IL-2R) we were unable to demonstrate abnormal levels of activated cells in the peripheral blood of multiple sclerosis patients irrespective of disease activity. The clinical relevance of activated $T$ cells and their role in the pathogenesis of multiple sclerosis remain to be determined. Nevertheless future studies using additional activation markers and determination of the functional characteristics of these cells may still help to further elucidate this aspect of the immunological process in multiple sclerosis.

The authors thank Sean MacRory for technical assistance and Patricia McConnell for preparation of the manuscript. This work was supported by Action MS.

\section{References}

1 Bach MA, Tournier E, Phan Dinh-Tuy F, et al. Deficient suppressor $\mathrm{T}$ cells in active multiple sclerosis. Lancet 1980;ii:1221-4.

2 Paty DW, Kastrukoff L, Morgan N, Hiob L. Suppressor $\mathrm{T}$ lymphocytes in multiple sclerosis: analysis of patients with acute relapsing and chronic progressive disease. Ann Neurol 1983;14:445-9.

3 Weiner HL, Hafler DA, Fallis RJ, Johnston D, Ault KA, Hauser SL. Altered blood T cell subsets in patients with multiple sclerosis. J Neuroimmunol 1984;6: 115-21.

4 Rice GPA, Finney D, Braheny SL, Knobler RL, Sipe JC, Oldstone MBA. Disease activity markers in multiple sclerosis; another look at suppressed cells defined by monoclonal antibodies OKT4, OKT5 and OKT8. $J$ Neuroimmunol 1984;6:75-84.

5 Zabrieski JB, Mayer L, Fu SM, Yeadon C, Cam V, Plank C. T cell subsets in multiple sclerosis: lack of correlation between helper and suppressor $\mathrm{T}$ cells and the clinical state. J Clin Immunol 1985;5:7-12.

6 Thompson AJ, Brazil J. Whelan CA, Martin EA, Hutchinson M, Feighery C. Peripheral blood T lymphocyte changes in multiple sclerosis: a marker of disease progression rather than of relapse? J Neurol Neurosurg Psychiatry 1986;49:905-12.

7 Golaz J, Steck A, Moretta L. Activated T lymphocytes in patients with multiple sclerosis. Neurology 1983; 33:1371-3.

8 Hafler DA, Hemler ME, Christenson $\mathrm{L}$ et al. Investigation of in vivo activated $T$ cells in multiple sclerosis and inflammatory central nervous system diseases. Clin Immunol Immunopathol 1985;37:163-71.

9 Hafler DA, Fox DA, Manning ME, Schlossman SF, Reinherz EL, Weiner HL. In vivo activated T lymphocytes in the peripheral blood and cerebrospinal fluid of patients with multiple sclerosis. $N$ Engl J Med 1985;312:1405-11.

10 Bellamy AS, Calder VL, Feldmann M, Davidson AN. The distribution of interleukin 2 receptor bearing lymphocytes in multiple sclerosis: evidence for a key role of activated lymphocytes. Clin Exp Immunol 1985;61:248-56.

11 Tournier-Lasserve E, Lyoncaen O, Roullet E, Bach MA. IL-2 receptor and HLA class II antigens on cerebrospinal fluid cells of patients with multiple sclerosis and other neurological diseases. Clin Exp Immunol 1987;67:581-86.

12 Fredrikson S, Karbson-Parra A, Olsson T, Link $H$. HLA-DR antigen expression on $T$ cells from cerebrospinal fluid in multiple sclerosis and aseptic meningo-encephalitis. Clin Exp Immunol 1987;68:298-304.

13 Selmaj K, Plater-Zyberk C, Rockett KA et al. Multiple sclerosis: increased expression of interleukin-2 receptors on lymphocytes. Neurology 1986;36:1392-5.

14 Fox DA, Hussey RE, Fitzgerald KA et al. Ta 1, a novel $105 \mathrm{KD}$ human $\mathrm{T}$ cell activation antigen defined by a monoclonal antibody. J Immunol 1984;133:1250-6.

15 McDonald WI, Halliday AM. Diagnosis and classification of multiple sclerosis. Br Med Bull 1977;33:4-8.

16 Hafler DA, Fox DA, Benjamin D, Weiner HL. Antigen reactive memory $\mathrm{T}$ cells are defined by Ta $1 . J$ Immunol 1986;137:414-8. 